\title{
The Consistency of MJO Teleconnection Patterns on Interannual Time Scales
}

\author{
KAI-ChiH Tseng, ERic Maloney, And Elizabeth A. BARnes \\ Colorado State University, Fort Collins, Colorado
}

(Manuscript received 10 July 2019, in final form 21 January 2020)

\begin{abstract}
The Madden-Julian oscillation (MJO) excites strong variations in extratropical geopotential heights that modulate extratropical weather, making the MJO an important predictability source on subseasonal to seasonal time scales (S2S). Previous research demonstrates a strong similarity of teleconnection patterns across MJO events for certain MJO phases (i.e., pattern consistency) and increased model ensemble agreement during these phases that is beneficial for extended numerical weather forecasts. However, the MJO's ability to modulate extratropical weather varies greatly on interannual time scales, which brings extra uncertainty in leveraging the MJO for S2S prediction. Few studies have investigated the mechanisms responsible for variations in the consistency of MJO tropical-extratropical teleconnections on interannual time scales. This study uses reanalysis data, ensemble simulations of a linear baroclinic model, and a Rossby wave ray tracing algorithm to demonstrate that two mechanisms largely determine the interannual variability of MJO teleconnection consistency. First, the meridional shift of stationary Rossby wave ray paths indicates increases (decreases) in the MJO's extratropical modulation during La Niña (El Niño) years. Second, a previous study proposed that the constructive interference of Rossby wave signals caused by a dipole Rossby wave source pattern across the subtropical jet during certain MJO phases produces a consistent MJO teleconnection. However, this dipole feature is less clear in both El Niño and La Niña years due to the extension and contraction of MJO convection, respectively, which would decrease the MJO's influence in the extratropics. Hence, considering the joint influence of the basic state and MJO forcing, this study suggests a diminished potential to leverage the MJO for S2S prediction in El Niño years.
\end{abstract}

\section{Introduction}

Subseasonal to seasonal (S2S) time scales (2-5 weeks) time scales longer than medium-range weather forecasts and shorter than seasonal outlooks-have long been recognized as a prediction desert (Vitart et al. 2017), and skillful predictions in this window provide tangible benefits to human society. A growing body of research has been conducted exploring the potential to leverage low-frequency modes of variability ( $>2$ weeks) for S2S prediction (Vitart 2017). Given that the Madden-Julian oscillation (MJO) is a mode of tropical convective variability characterized by planetary-scale circulations and intraseasonal time scales (Madden and Julian 1971; Adames and Kim 2016), it has been considered one of the most important predictability sources on S2S time scales. While the MJO produces a direct modulation of tropical weather such as the tropical cyclone genesis (Liebmann et al. 1994; Maloney and Hartmann 2000), the initiation of El Niño-Southern Oscillation (ENSO) events (Moore and Kleeman 1999), and the diurnal cycle in

Corresponding author: Kai-Chih Tseng, kctseng@rams.colostate.edu the Maritime Continent (Kanamori et al. 2013), the MJO's impacts extend well beyond the tropics. Indeed, some of the most impactful weather phenomena in the extratropics, such as atmospheric rivers (Mundhenk et al. 2016, 2018), anticyclonic blocking (Moore et al. 2010; Hamill and Kiladis 2014; Henderson et al. 2016), and extreme cold air outbreaks (Yoo et al. 2012), are modulated by the MJO through tropical-extratropical teleconnections. Previous studies (e.g., Hoskins and Karoly 1981; Sardeshmukh and Hoskins 1988) demonstrated that large-scale heating balanced by rising motion-induced adiabatic cooling over the tropics is associated with divergent outflow in upper troposphere. The divergent outflow, which interacts with the subtropical jet and generates a Rossby wave source, enables tropical signals to extend their influence into the extratropics where propagation is no longer constrained by the mean tropical easterly flow. Seo and Lee (2017) further showed that the Rossby wave source that develops in $0-5$ days in response to a given MJO heating can excite quasi-stationary Rossby waves and consistently modulate extratropical circulations on S2S time scales (2-5 weeks). 
A recent study showed that the landfall frequency of atmospheric rivers in coastal California can increase or decrease by $40 \%$ in specific MJO phases compared to climatology due to the low-frequency variation of the circulation associated with MJO teleconnections (Mundhenk et al. 2018). An empirical model using the $\mathrm{MJO}$ as a predictor provides skillful prediction of atmospheric rivers at forecast leads of 3 weeks, and an additional 2 weeks of skill are obtained when the quasi-biennial oscillation (QBO) is included as a predictor (Mundhenk et al. 2018). In addition to empirical prediction, MJO teleconnections also benefit the prediction skill of operational forecast systems. For example, a recent study demonstrated that a more consistent teleconnection pattern from event to event (i.e., pattern consistency) found in $\mathrm{MJO}$ phases 2, 3, 6, and 7 (MJO phases will be defined in section 2) is also characterized by excellent agreement in the prediction of geopotential height anomalies across model ensemble members at forecast leads of up to 3 weeks (Tseng et al. 2018).

The MJO's ability to modulate extratropical weather, however, may vary on interannual time scales. For example, previous studies demonstrated that the QBO and ENSO can dramatically change MJO intensity and propagation speed, which can modulate the MJO's extratropical teleconnections (Pohl and Matthews 2007; Yoo and Son 2016). Thus, the influence of these modes of interannual variability on the consistency of MJO teleconnections necessitates investigation. This study focuses on the influence of ENSO on MJO teleconnections. ENSO represents a recharge or discharge of warm water volume in the equatorial Pacific, with a period of 2-7 years (Jin 1997). ENSO has been documented to influence convective activity of the MJO, including its intensity and propagation speed (Pohl and Matthews 2007). In El Niño years, MJO convection tends to be stronger over the western and central Pacific and is characterized by a faster propagation speed, while La Niña years produce the opposite behavior (Pohl and Matthews 2007; Henderson and Maloney 2018). In addition, different types of El Niño events [e.g., central Pacific El Niño (CP El Niño) and eastern Pacific El Niño (EP El Niño)] are also capable of modulating MJO convective activity. Pang et al. (2016) showed that intraseasonal OLR variance is stronger but more concentrated over the Maritime Continent during CP El Niño than EP El Niño. ENSO also modulates the strength and position of the subtropical jet and extratropical geopotential heights through its impact on tropical-extratropical teleconnections (Bjerknes 1969). Moon et al. (2011) demonstrated that MJO teleconnections are directly influenced by ENSO teleconnections through constructive (destructive) interference. Their study further showed that ENSO-induced basic state changes also change the pathway through which the MJO communicates with extratropical regions. Due to ENSO's widespread influence on both the basic state and the MJO forcing, the consistency of MJO teleconnections and the predictability of the associated extreme weather are expected to be modulated by ENSO in potentially complex ways.

This work uses reanalysis data, ensemble simulations of a linear baroclinic model, and a Rossby wave ray tracing algorithm to investigate the mechanisms underlying ENSO-induced interannual variability of MJO teleconnections and their consistency. The results are interpreted through the theoretical lens of linear Rossby wave theory, where the wave growth and propagation are assumed to follow the first-order approximation of the linearized barotropic vorticity equation. In particular, a meridional shift of the Rossby wave ray paths modulated by ENSO that leads to changes in the consistency of the MJO teleconnection will be highlighted in this research. In addition, the role of an intraseasonal Rossby wave source modulated by ENSO in influencing the consistency of the MJO teleconnection will also be elucidated. This manuscript is organized as follows. In section 2, a description of data, the linear baroclinic model (LBM), and methods are provided. In section 3 , the pattern consistency of MJO teleconnections in different ENSO states in reanalysis fields is discussed. In section 4 , the mechanisms that determine variations in the pattern consistency of MJO teleconnections with ENSO are investigated through ensemble simulations of the LBM and use of a Rossby wave tracing algorithm. Section 5 presents conclusions and discussion.

\section{Data, model, and methods}

\section{a. Observational reference}

\section{1) 500-HPA GEOPOTENTIAL HEIGHT ANOMALIES}

Thirty-seven years (1979-2015) of daily 500-hPa geopotential height (Z500 hereafter) data from the European Centre for Medium-Range Weather Forecasts (ECMWF) third-generation reanalysis product (ERAInterim; Dee et al. 2011) are used to represent MJO teleconnections. Since the tropical-extratropical teleconnections are characterized by a nearly equivalent barotropic structure, the precise selection of vertical pressure level does not qualitatively affect the conclusions of this study. The daily anomalous Z500 is acquired by removing the first three harmonics of the seasonal cycle. In this study, we are also interested in ENSO's indirect effect on tropical-extratropical teleconnections 
through modifying the MJO forcing and the basic state upon which MJO teleconnections propagate. Thus, we also apply an intraseasonal bandpass filter (20-100 days) to the total Z500 anomaly field to remove extratropical anomaly signals directly generated by ENSO. In this study, both total and intraseasonal Z500 anomaly data are interpolated to a horizontal resolution of $2.5^{\circ} \times 2.5^{\circ}$.

\section{2) MJO PHASES}

The evolution of MJO convection is defined by the outgoing longwave radiation (OLR)-based MJO index (OMI), which is acquired from https://www.esrl.noaa.gov/ $\mathrm{psd} / \mathrm{mjo} / \mathrm{mjoindex} /$. One advantage of using OMI rather than other $\mathrm{MJO}$ indices is that tropical convection plays a major role in perturbing the upper-troposphere vorticity field and generating tropical-extratropical teleconnections. Other MJO indices defined by several fields, such as the real-time monitoring MJO index (RMM), are typically dominated by the wind field while convective variability explains little variance of the index (Straub 2013). MJO phase is then defined by $\tan ^{-1}$ (OMI2/ OMI1), where OMI1 and OMI2 are the principal components of the first two empirical orthogonal functions of the equatorially averaged $\left(15^{\circ} \mathrm{N}-15^{\circ} \mathrm{S}\right)$ OLR fields. Only days with $\sqrt{\mathrm{OMI}^{2}+\mathrm{OMI}^{2}}$ greater than $1 \sigma$ are used in our analysis.

\section{b. Model, Rossby wave source analysis, and ray tracing algorithm}

\section{1) MODEL DESCRIPTION}

The linear baroclinic model (LBM) developed by Watanabe and Kimoto (2000) is used in this study. In the LBM, the hydrostatic primitive equations are linearized about a basic state and the anomalous response for a given forcing is calculated, allowing the influence of basic state variability and MJO forcing to be separated. The appendix of Watanabe and Kimoto (2000) and LBM users' guide (https://ccsr.aori.u-tokyo.ac.jp/ lbm/ lbm/doc2.2.pdf) provide details on the LBM. A model configuration is used where the forcing and response are time dependent, instead of directly solving for a steadystate extratropical response to MJO heating. A similar time-dependent configuration can be to develop a storm track model (e.g., Watanabe and Kimoto 2000). However, different settings are used in the model here to solve for the extratropical MJO response, including the forcing method and numerical damping parameters. An eastward propagating MJO heating is used in this study (see section 4), while random white noise forcing was used in the storm track model. Following the LBM setup of Tseng et al. (2019), T42 horizontal resolution $\left(\sim 2.8^{\circ}\right)$ and $20 \sigma$ levels are used. Numerical damping, including Rayleigh friction and Newtonian cooling, is employed in the LBM with an $e$-folding time scale of 20 days in most vertical layers, while the top one and the bottom three layers (i.e., 1.0, 0.95, and 0.9 of $\sigma$ levels) have a damping time scale of 0.5 day. Fourth-order biharmonic damping (i.e., $\nabla^{4}$ ) is deployed with an $e$-folding time scale of $2 \mathrm{~h}$ for the shortest wavelength. These parameter settings prevent unstable baroclinic growth of eddies and the integration is stabilized. Damping strength weaker than this setup can lead to numerical instability. These parameters were employed in previous studies demonstrating reasonable simulation of $\mathrm{MJO}$ teleconnection patterns (Tseng et al. 2019).

\section{2) MOdel BASIC STATE AND MJO FORCING}

To generate model basic states, the ERA-Interim reanalysis from 1979 to 2015 is used. Three variablessurface pressure, horizontal momentum, and temperature-are used to define the basic state in the LBM. The basic states are associated with the linear operator of the LBM, which remains unchanged during the period of the integration. To examine how different climate states influence the pattern consistency of the MJO teleconnections, we further define the ENSO phase based on the monthly Niño-3.4 index, which was acquired from https:/www.esrl.noaa.gov/psd/gcos_wgsp/Timeseries/Nino34/. A warm ENSO phase (i.e., El Niño) is defined as when the Niño-3.4 index is greater than $1 \sigma^{\circ} \mathrm{C}$, and a cold ENSO phase (i.e., La Niña) occurs when the Niño-3.4 index is colder than $-1 \sigma^{\circ} \mathrm{C}$, and neutral conditions do not meet either criterion. Since MJO teleconnections are stronger during boreal winter than other seasons, we only use data during November-March (referred to as boreal winter hereafter). Basic states are then defined by the boreal winter average values. Previous studies have indicated that the evolution of the basic state across winter months is not modest (Newman and Sardeshmukh 1998), which is a limitation of the current model setup. However, the impact of seasonality is beyond the scope of this study.

For the model forcing, the daily apparent heat source [i.e., $Q_{1}$, Eq. (1)] is derived from the budget residual of the thermodynamic energy equation (Yanai et al. 1973):

$$
Q_{1} \equiv \frac{D s}{D t} \cong Q_{R}+Q_{c}-\frac{\partial \overline{s^{\prime} w^{\prime}}}{\partial p}
$$

In (1), $D s / D t$ is the material derivative of the dry static energy (i.e., $s$, which is defined as $c_{p} T+g z ; c_{p}$ is the specific heat and $g$ is the gravitational acceleration), $Q_{R}$ is the radiative heating or cooling, $Q_{c}$ is the latent heat release, $-\left(\partial \overline{s^{\prime} w^{\prime}} / \partial p\right)$ is the convergence of the eddy heat flux by convection or boundary layer turbulence, and $w$ is the pressure velocity. In general, the apparent heat 


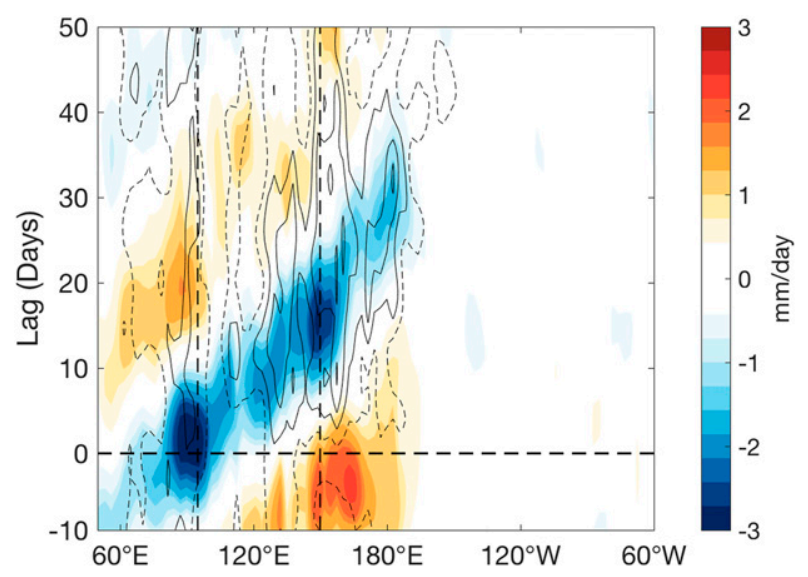

FIG. 1. The equatorial-averaged $\left(15^{\circ} \mathrm{S}-15^{\circ} \mathrm{N}\right)$ column-integrated apparent heat source relative to MJO events defined at MJO phase 6, lag 0 . The contour represents the standard deviation over different ensemble members, which begins at $0.7 \mathrm{~mm}$ day $^{-1}$ with an interval of $0.1 \mathrm{~mm}$ day $^{-1}$.

source is positive when convective heating is dominant. An intraseasonal bandpass filter (20-100 days) is applied to obtain the MJO heating anomaly. In addition, a Gaussian mask with maximum on the equator and $e$-folding scale of $15^{\circ}$ in the meridional direction is applied to the heating to ensure extratropical signals are excited only by remote forcing in the tropics. In this study, we use daily precipitation rate $\left(\mathrm{mm} \mathrm{day}^{-1}\right)$ to present the heating intensity. Specifically, we divide column-integrated $Q_{1}$ by the latent heat of condensation (i.e., $L$ ).

\section{3) EXPERIMENTAL DESIGN}

ENSO can modulate MJO teleconnections through two distinct pathways: 1) by modulating the basic state and 2) by modulating the MJO forcing (see discussion in section 3). Therefore, we can examine the influence from each component by either fixing or changing the basic states or the MJO forcing in the LBM. Overall, seven different ensemble simulations are conducted, named 1) bs.neutral.frc.neutral, 2) bs.El Niño.frc.neutral, 3) bs.La Niña.frc.neutral, 4) bs.neutral.frc.El Niño, 5) bs.neutral.frc.La Niña, 6) bs.El Niño.frc.El Niño, and 7) bs.La Niña.frc.La Niña. The simulations are named after the nature of the basic states and MJO forcing used in the particular simulation. For example, the simulation "bs.neutral.frc.neutral" indicates both the basic states ("bs") and the MJO forcing ("frc") are acquired from ENSO neutral years. For an individual simulation within an ensemble, the MJO forcing is generated by compositing 20 randomly sampled MJO days for a given MJO phase when the OMI reaches or exceeds $1 \sigma$ at lag 0 . The resampling process is repeated 30 times to acquire 30 ensemble members. According to the central limit theorem, when the independent random variables are added, their normalized sum tends toward a normal distribution even if the original structure is not normal. The preprocessing used ensures that the perturbations to the MJO forcing form a normal distribution for each MJO phase, which is consistent with the preprocessing used to generate ensemble simulations for numerical weather forecasts in operational centers (Christiansen 2019). In addition, this preprocessing ensures each ensemble member experiences the average behavior of MJO convection over different ENSO states with slight differences across different members and avoids issues associated with small sample sizes.

Previous studies have shown that the teleconnections generated by earlier MJO phases can interfere with teleconnections generated by subsequent $\mathrm{MJO}$ phases due to the circumnavigating nature of MJO convection (Tseng et al. 2018). Also, heating-induced teleconnections take 10 days to develop (Tseng et al. 2019). Therefore, an additional 10 days of $\mathrm{MJO}$ forcing prior to lag 0 are given to the LBM to mimic real-world conditions. Figure 1 demonstrates one of the equatorial-averaged $\left(15^{\circ} \mathrm{S}-15^{\circ} \mathrm{N}\right)$ MJO phase- 6 forcing evolutions given to the LBM acquired from neutral years (shading). Three-dimensional time-evolving heating fields are used for the experiments, and the equatorial average values in Fig. 1 are only presented for ease of illustration. In Fig. 1, the MJO forcing is characterized by a phase- 6 heating structure with a negative heating in the eastern Indian Ocean and a positive heating in the western Pacific at lag 0 . With increasing lag, the MJO forcing propagates eastward and decays around the date line, which is consistent with observed features in previous studies (Hendon et al. 2007). The contours represent the standard deviation of the MJO forcing over different ensemble members, which demonstrates the longitudes where the MJO forcing is most variable. The above forcing preprocessing enables examination of the effects of interannual variability of MJO forcing, including the change in intensity over different ocean basins and the eastward extension or the westward retraction of MJO convection in the western Pacific.

\section{4) LineARIZED Rossby WAVE SOURCE}

To better understand the dynamics of the circulation response to MJO forcing, we use the linearized barotropic vorticity equation (Sardeshmukh and Hoskins 1988):

$$
\frac{\partial \zeta^{\prime}}{\partial t}=S^{\prime}-\overline{\mathbf{v}}_{\psi} \cdot \nabla \zeta^{\prime}-\mathbf{v}_{\psi}^{\prime} \cdot \nabla \bar{\zeta}+F^{\prime}
$$

where the prime indicates perturbations (intraseasonal time scales) and the overbar is the climatology; $\zeta$ is the absolute vorticity, $\mathbf{v}_{\psi}$ is the rotational wind including zonal $\left(u_{\psi}\right)$ and meridional components $\left(v_{\psi}\right), F^{\prime}$ is 
frictional damping, and $S^{\prime}$ is the Rossby wave source. In (2), the rotational wind redistributes the vorticity field associated with Rossby wave propagation, and $S^{\prime}$ is related to Rossby wave production. The Rossby wave source $S^{\prime}$ can be expanded in the following form:

$$
\begin{aligned}
S^{\prime}= & -\nabla \cdot\left(\bar{\zeta} \mathbf{v}_{\chi}^{\prime}+\overline{\mathbf{v}}_{\chi} \zeta^{\prime}\right)=-\bar{\zeta} \nabla \cdot \mathbf{v}_{\chi}^{\prime}-\mathbf{v}_{\chi}^{\prime} \cdot \nabla \bar{\zeta} \\
& -\zeta^{\prime} \nabla \cdot \overline{\mathbf{v}}_{\chi}-\overline{\mathbf{v}}_{\chi} \cdot \nabla \zeta^{\prime},
\end{aligned}
$$

In (3), $\mathbf{v}_{\chi}$ is the nonrotational component of the horizontal wind. The physical meaning of (2) and (3) is that generation of the anomalous Rossby wave $\left(\partial \zeta^{\prime} / \partial t\right)$ is associated with the stretching and advection of the climatological absolute vorticity by the anomalous divergent flow [i.e., $\left.-\nabla \cdot\left(\bar{\zeta} \mathbf{v}_{\chi}^{\prime}\right)\right]$ and the stretching and advection of the anomalous absolute vorticity by the climatology divergent flow [i.e., $\left.-\nabla \cdot\left(\overline{\mathbf{v}}_{\chi} \zeta^{\prime}\right)\right]$. The Rossby wave source term $S^{\prime}$ is especially notable in regions of convective activity where there is strong divergent outflow that impinges upon a strong background vorticity gradient (e.g., the subtropical jet).

\section{5) ROSSBY WAVE RAY TRACING ALGORITHM}

We use a Rossby wave ray tracing algorithm (Karoly 1983) to investigate how interannual variability of wave propagation influences the pattern consistency of MJO teleconnections. As noted previously, wave propagation is largely regulated by the rotational flow. Thus, to understand Rossby wave propagation in a nearly barotropic flow, which is a good assumption in the midlatitude upper troposphere, the rotational component of (2) can be isolated. Further, by replacing the anomalous vorticity $\zeta^{\prime}$ with the anomalous streamfunction $\nabla^{2} \psi^{\prime}$, (2) can be rewritten in the following form:

$$
\frac{\partial \nabla^{2} \psi^{\prime}}{\partial t}+\left(\overline{\mathbf{v}}_{\psi} \cdot \nabla\right) \nabla^{2} \psi^{\prime}+\psi_{x}^{\prime} \bar{\zeta}_{y}-\psi_{y}^{\prime} \bar{\zeta}_{x}=0 .
$$

In (4), $\nabla^{2}$ is the horizontal Laplace operator, $\psi_{x}^{\prime}$ indicates the rotational component of the anomalous meridional wind $v_{\psi}^{\prime},-\psi_{y}^{\prime}$ represents the rotational component of the anomalous zonal wind $u_{\psi}^{\prime}, \bar{\zeta}_{y}$ is the meridional gradient of the mean absolute vorticity, and $\bar{\zeta}_{x}$ is the zonal gradient of the mean absolute vorticity. Since $\psi_{y}^{\prime} \bar{\zeta}_{x}$ and $\bar{v}_{\psi}(\partial / \partial y) \nabla^{2} \psi^{\prime}$ in $\left(\overline{\mathbf{v}}_{\psi} \cdot \nabla\right) \nabla^{2} \psi^{\prime}$ are negligible compared to the other terms, (4) can be simplified as

$$
\frac{\partial \nabla^{2} \psi^{\prime}}{\partial t}+\bar{u}_{\psi} \frac{\partial}{\partial x} \nabla^{2} \psi^{\prime}+\psi_{x}^{\prime} \bar{\zeta}_{y} \approx 0 .
$$

Using so-called Wentzel-Kramers-Brillouin (WKB) theory for approximating solutions to (5), the following dispersion relationship can be generated:

$$
\omega=\bar{u}_{\psi} k-\frac{\bar{\zeta}_{y} k}{k^{2}+l^{2}}
$$

where $\omega$ is the frequency, $k$ is the zonal wavenumber, $l$ is the meridional wavenumber, and the total wavenumber $K$ is defined by $\sqrt{k^{2}+l^{2}}$. The components of group velocity for a stationary Rossby wave $(\omega=0)$ may then be represented as $c_{g x}=d x / d t=\bar{u}_{\psi}+\left(k^{2}-l^{2}\right) \bar{\zeta}_{y} / K^{4}$ and $c_{g y}=d y / d t=(2 k l) \bar{\zeta}_{y} / K^{4}$. In this study, these group velocities are used to determine Rossby wave paths, as in Karoly (1983). By using analogies to optical physics, Hoskins and Ambrizzi (1993) demonstrated that the subtropical jet characterized by high stationary wavenumber acts as a waveguide, which can trap Rossby waves and affect their propagation direction. We will demonstrate below that the interannual variability of the subtropical jet plays a vital role in determining the pattern consistency of MJO teleconnections from event to event.

\section{c. Assessment of predictability: Quantifying pattern consistency}

Following the method of Tseng et al. (2019), the pattern consistency of MJO teleconnections is calculated to quantify the robustness of the teleconnection signals. An area-weighted pattern correlation coefficient is determined for every pair of MJO events (or ensemble members) in a domain over the North Pacific and North America $\left(20^{\circ}-70^{\circ} \mathrm{N}, 150^{\circ} \mathrm{E}-120^{\circ} \mathrm{W}\right)$. For an ensemble with 30 members, there are 435 correlation coefficients. By estimating the fraction of pairs with a correlation coefficient that meet or exceed a certain criteria $(0.5$ in this study), the pattern consistency of the MJO teleconnection over different phases and time lags can be quantified. The study of Tseng et al. (2018), in which ENSO state was not considered, showed that the MJO phases with higher pattern consistency from event to event in observations are also characterized by better agreement across numerical weather prediction model ensemble members in predicted extratropical geopotential height anomalies.

\section{The consistency of teleconnections in reanalysis}

Figure 2 demonstrates the pattern consistency of the daily and intraseasonal Z500 anomalies over different ENSO states as a function of MJO phases and time lag. Darker colors indicate that more paired events have similar teleconnection patterns, while lighter colors indicate fewer paired events have similar teleconnection patterns. An $n$-day lag indicates $n$ days after the given MJO phase. Figures 2a-d show the unfiltered anomalous Z500 (i.e., only the seasonal cycle is removed) and 

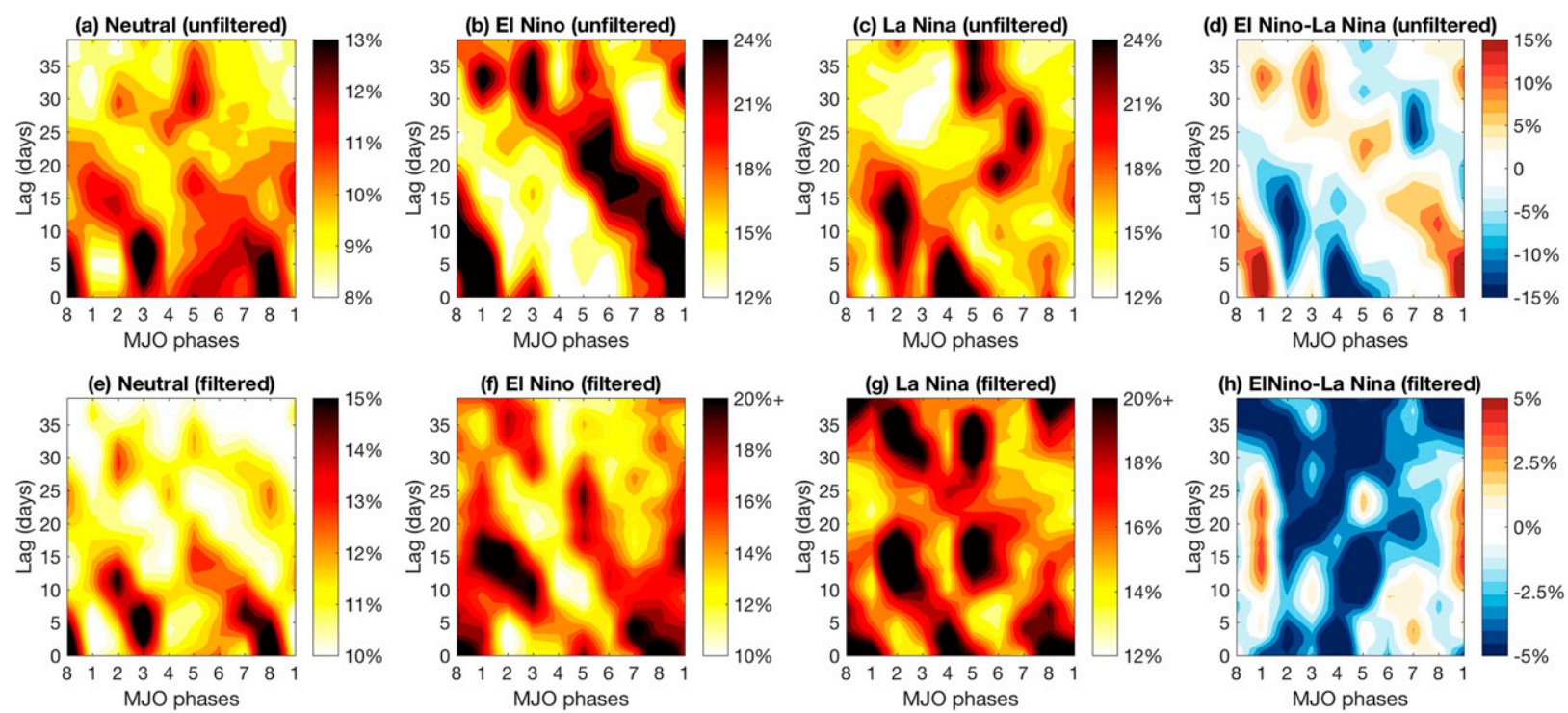

FIG. 2. The pattern consistency of the (a)-(c) unfiltered and (e)-(g) intraseasonal Z500 anomalies over the domain of the North Pacific and the North America $\left(20^{\circ}-70^{\circ} \mathrm{N}, 150^{\circ} \mathrm{E}-120^{\circ} \mathrm{W}\right)$ in neutral, El Niño, and La Niña years, respectively. (d) The difference between (b) and (c). (h) The difference between (f) and (g).

Figs. 2e-h display the intraseasonal Z500 anomalies. In Fig. 2a during ENSO neutral conditions, two striped patterns extend from lag 0 , MJO phase 3 and phase 8 to lag 20, MJO phase 1 and phase 5, respectively. This feature is consistent with Tseng et al. (2019), who demonstrated that the two stripes of high pattern consistency are generated when MJO heating exhibits a dipole pattern with opposite heating centers on either side of the Maritime Continent (e.g., MJO phase 2, 3, 6, and 7). The tilting structure of the stripes is due to the progression of MJO phases and associated eastward propagation of convection. Seo and Lee (2017) and Tseng et al. (2019) showed that the MJO signals take about 10-14 days to develop in the extratropical Pacific. Thus, the enhanced consistency observed in earlier lags of other phases (e.g., phase 8 , lag $0-5$ ) is caused by delayed signals produced by other phases due to the slow variation of the MJO. However, with variations in ENSO state (Figs. 2b,c), for unfiltered Z500 anomalies only one of the two stripes indicating high pattern consistency still exists in both cold and warm ENSO periods. In El Niño years, only the stripe initiated in phase 8 exists with a slight shift toward phase 1 , whereas the stripe initiated in phases 3 and 4 only appears in La Niña years.

We hypothesize that constructive or destructive interference of MJO and ENSO teleconnection patterns are responsible for some of the behavior shown in the top row of Fig. 2. The role of tropical heating in generating tropical-extratropical teleconnections has been extensively investigated since the 1980s, including that associated with both intraseasonal and interannual time scale heating. The El Niño SST warming pattern and associated active convection in the eastern and central Pacific are known to induce a positive Pacific-North America pattern (PNA pattern), which is characterized by a low pressure anomaly in the North Pacific, high pressure anomaly near the west coast of North America, and a low pressure anomaly in the eastern United States. La Niña years are associated with a negative PNA pattern. Henderson and Maloney (2018) demonstrated that MJO convection in phases 2 and 3 favors a negative PNA pattern while the convection in phases 6 and 7 leads to a positive PNA pattern. Since both the interannual and intraseasonal time scales Z500 anomalies are included in the unfiltered Z500 anomalies, the constructive (destructive) interference between the teleconnection patterns generated on these two time scales likely lead to enhanced (diminished) pattern consistency during certain periods in Figs. $2 b$ and $2 c$ relative to Fig. 2a, consistent with the superposition of ENSO and MJO teleconnections shown by Henderson and Maloney (2018) (refer to their Fig. 12). Figure 2d depicts the difference of the unfiltered Z500 anomaly pattern consistency between El Niño and La Niña years and a shift of the high pattern consistency from El Niño years to La Niña years is observed, which can be explained by the tropical-extratropical teleconnections directly generated by interannual convection variability. In El Niño years, the constructive interference between MJO and ENSO teleconnections happens around MJO phase 6 and 7, although this feature shows up in MJO 
phase 2 and 3 during La Niña years. Thus, Fig. 2d shows the shift of regions characterized by high pattern consistency due to the change in ENSO state. The amplitude change in the pattern consistency of daily Z500 on interannual time scales can reach $15 \%$, which is about the same order of magnitude with the pattern consistency shown in Figs. 2a-c. Therefore, Fig. 2d highlights the importance of ENSO for modulating the daily Z500. It is worth mentioning that the spectrum of daily Z500 is nearly red (figure not shown). Thus, low-frequency (i.e., longer than synoptic time scales) signals may dominate the results in Figs. 2a-c.

In addition to ENSO's ability to interfere with the MJO teleconnection through superposition, it can indirectly influence MJO teleconnections by modulating the basic state upon which MJO teleconnections propagate and develop, as well as the strength and propagation characteristics of MJO convection. To remove the direct influence of ENSO on the extratropical geopotential height, an intraseasonal bandpass filter (20-100 days) is applied. The resulting pattern consistencies are shown in Figs. 2e-g. Both Figs. 2a and 2e show similar stripe features, except that the stripes are more distinct in Fig. 2e. Since Fig. 2a contains Z500 variability on time scales shorter than subseasonal, it is logical that the stripes of pattern consistency will be clearer in Fig. 2e than in Fig. 2a. This two-stripe feature is also documented in a previous study (Tseng et al. 2019), in which all data from 1979 to 2015 were used (unsegregated by ENSO phase), indicating that the mean state of neutral years is similar to the winter climatology of the Pacific domain. The other apparent difference is that two stripes show up in both Figs. $2 \mathrm{f}$ and $2 \mathrm{~g}$ during both warm and cold ENSO states compared to a single stripe in Figs. $2 \mathrm{~b}$ and $2 \mathrm{c}$. This change supports the previous hypothesis that the diminished pattern consistency in regions of phase space in Figs. $2 b$ and $2 c$ is caused by the destructive interference between interannual and intraseasonal teleconnections. Last, we compare the difference in MJO teleconnection pattern consistency between El Niño years and La Niña years (Fig. 2h). Figure $2 \mathrm{~h}$ suggests a systematic increase of pattern consistency from El Niño years to La Niña. A number of factors may explain this increased pattern consistency including changes in MJO intensity, propagation speed of MJO convection, the eastward longitudes to which MJO convection penetrates (eastward extension or westward retraction), and the strength and location of the subtropical jet. The coexistence of different factors makes the key mechanisms difficult to assess in reanalysis fields. The difference in sample sizes over different climate states, such as neutral years having twice the sample size of the other two ENSO states, also increases the difficulty of interpreting the robustness of the results. Therefore, we use an LBM in the next section to help address these challenges.

\section{The consistency of simulated teleconnections}

In this section, we address the following two questions 1) Can an LBM simulate the interannual variability of MJO teleconnection pattern consistency found in the reanalysis data? and 2) What is the key mechanism that determines the interannual variability of the teleconnection pattern consistency?

\section{a. The simulated and observed MJO teleconnection pattern}

First, we present an overview of the simulated and observed teleconnection patterns from the LBM and reanalysis. To provide a fair comparison between the two, a 20-100-day bandpass filter is applied to the observed Z500. Figure 3 shows the MJO phase 2, lag 5-12 and phase 7, lag 5-12 composited Z500, where the contours denote the ensemble mean of the LBM simulations [from top to bottom are bs.neutral.frc.neutral (Fig. 3a), bs.El Niño.frc.El Niño (Fig. 3b), and bs.La Niña.frc.La Niña (Fig. 3c)] and the shading denotes observed Z500 anomalies over different ENSO states. Phase 2, lag 5-12 and phase 7, lag 5-12 are the MJO phases and lags exhibiting the strongest composited teleconnection signals. In general, the LBM reasonably simulates the MJO teleconnection patterns over the PNA regions for the three ENSO states, although the locations showing the strongest signals are not perfectly collocated with observations. These biases may result from the linear assumption of LBM. The basic states in the observed system can vary over a short period of time due to wave-mean flow interactions caused by MJO teleconnections. In addition, the LBM underestimates the amplitude of teleconnections in all cases as discussed in Tseng et al. (2019), which may be due to the lack of dynamical feedbacks of transient eddies and diabatic heating (Jin et al. 2006; Hirota and Takahashi 2012). Over the North Atlantic specifically, the LBM fails to capture the teleconnection signal. Henderson and Maloney (2018) showed that only a nonlinear baroclinic model (i.e., dry dynamical core) can simulate the MJO teleconnection over the Atlantic sector, which implies the importance of nonlinear dynamics over this region. Other discrepancies between the simulated and observed teleconnection patterns are also evident. For example, the observed MJO teleconnection being stronger and more organized over northeastern North America in El Niño years than La Niña years, which is opposite to the simulations. The MJO teleconnection in 
Phase 2, Lag 5-12

(a) Neutral and bs.neutral.frc.neutral

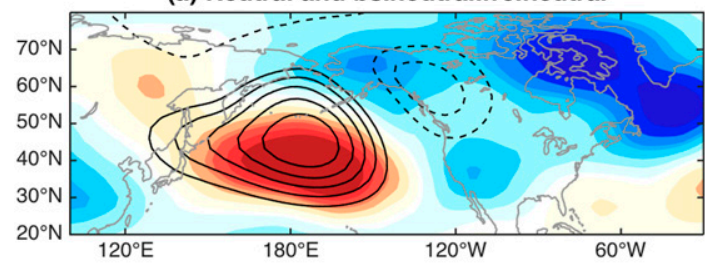

(b) EI Nino and bs.EI Nino.frc. EI Nino

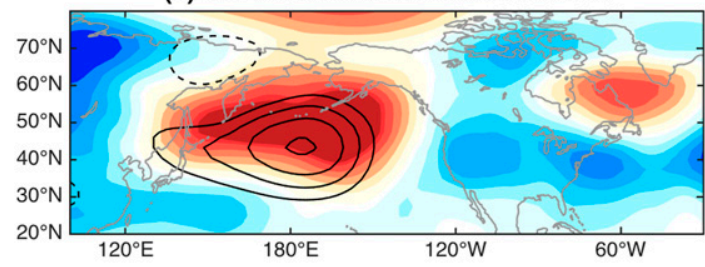

(c) La Nina and bs.La Nina.frc.La Nina

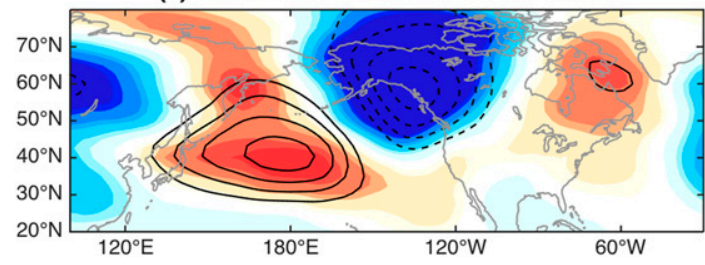

Phase 7, Lag 5-12

(d) Neutral and bs.neutral.frc.neutral

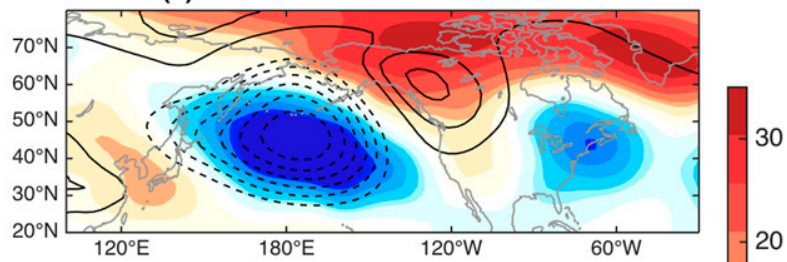

(e) EI Nino and bs.EI Nino.frc.El Nino

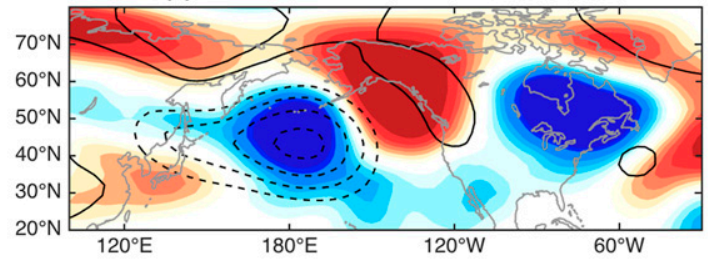

(f) La Nina and bs.La Nina.frc.La Nina

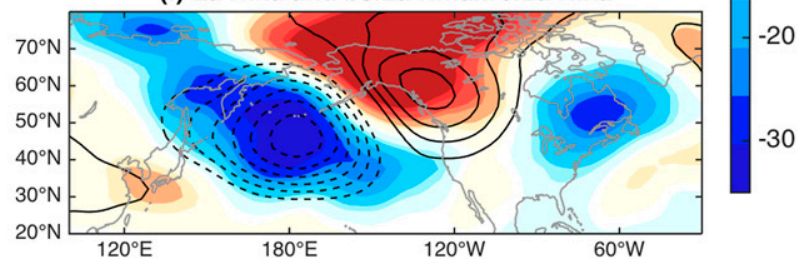

FIG. 3. The MJO phase 2 and lag 5-12 composited Z500 for (a) observations in neutral years (shading) and bs.neutral.frc.neutral (contour), (b) observations in El Niño year (shading) and bs.El Niño.frc.El Niño (contours), and (c) observations in La Niña year (shading), and bs.La Niña.frc.La Niña (contours). (d)-(f) As in (a)-(c), but for phase 7, lag 5-12. Contours start at $4 \mathrm{~m}$ (solid) and -4 m (dashed) with an interval of $4 \mathrm{~m}$ (0 omitted). Dashed contours denote negative values and solid contours are positive value. The analysis domain covers the extratropical Pacific and part of the North America $\left(20^{\circ}-70^{\circ} \mathrm{N}, 150^{\circ} \mathrm{E}-120^{\circ} \mathrm{W}\right)$.

the Atlantic and northeastern North America are beyond the scope of this study and will be addressed in future work. Despite some modest biases in amplitude and location, the LBM reasonably simulates the MJO teleconnection pattern over different climate states in the PNA regions. However, there is also no obvious difference in anomaly amplitude across the three observed ENSO states or the three LBM simulations. A strong signal is not necessarily indicative of a more consistent teleconnection pattern, since amplitude information is absent in the calculation of pattern consistency. Thus, we will focus on the mechanisms responsible for the change in teleconnection pattern consistency in the following sections.

\section{b. An overview of the simulated MJO teleconnection pattern consistency}

Seven ensemble simulations are generated by varying the basic states and/or the MJO forcing (see section 2) to assess the two questions posed at the beginning of this section. Each ensemble simulation generates 30 ensemble members by perturbing the MJO forcing in each MJO phase. Figure 4 demonstrates the pattern consistency of the simulated MJO teleconnections in the LBM as a function of MJO phase and time lag. Figure $4 \mathrm{a}$ shows the pattern consistency of the MJO teleconnections when both the basic states and the MJO forcing are acquired from ENSO neutral years. The second row shows the pattern consistency of the MJO teleconnections when the basic states and/or the MJO forcing are replaced by El Niño year conditions. The third row is the pattern consistency of the MJO teleconnection when the basic states and/or the MJO forcing are replaced by La Niña year conditions. As discussed in Tseng et al. (2019), the simulated pattern consistency is on average higher than the reanalysis pattern consistency, which, in part, reflects the absence of noise by the synoptic eddies in the idealized linear model compared to the real world. In addition, the use of composite forcing can also reduce the ensemble spread and increase the consistency. Regardless of the systematic bias in amplitude, the LBM can qualitatively simulate the interannual variability of MJO teleconnection pattern consistency in reanalysis, especially the decreased consistency of the MJO teleconnection pattern in El Niño years compared to La Niña years (i.e., Fig. 4d shows much lower consistency than Fig. 4g, which is similar to Fig. 2h). The timing of enhanced 

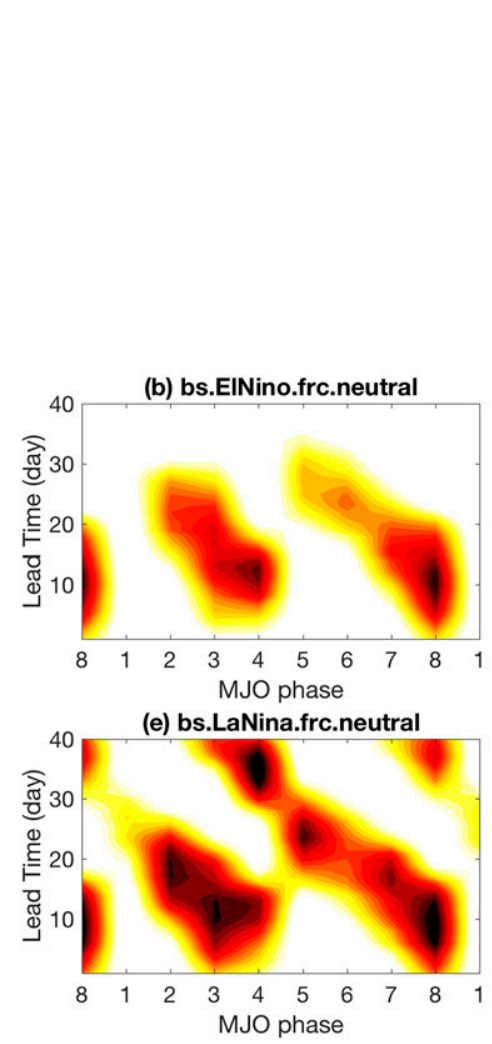
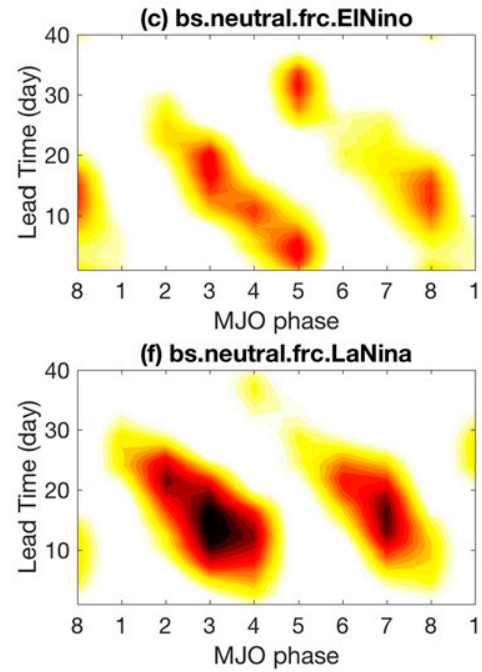
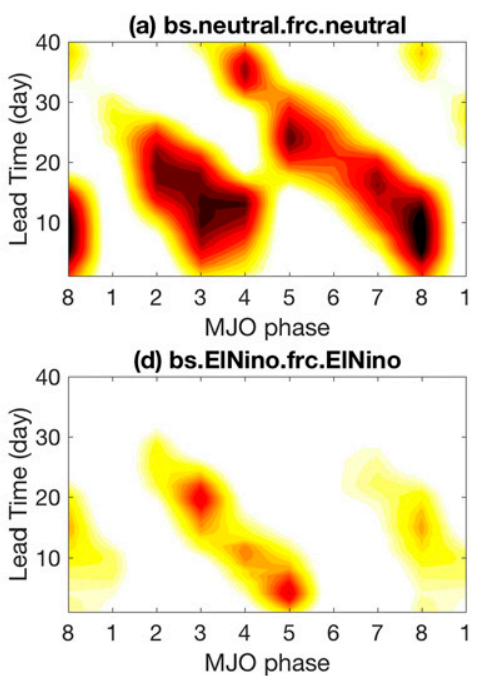

(g) bs.LaNina.frc.LaNina

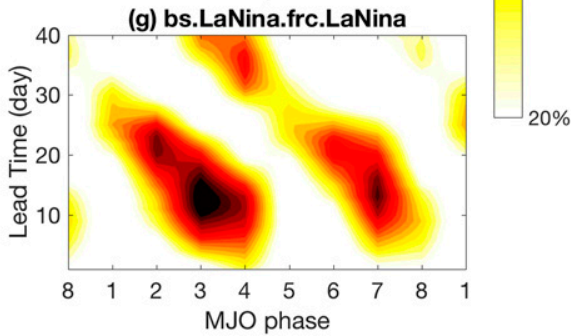

FIG. 4. The pattern consistency of Z500 anomalies over the 30 ensemble members in the simulations of (a) bs.neutral.frc.neutral, (b) bs.El Niño.frc.neutral, (c) bs.neutral.El Niño, (d) bs.El Niño.frc.El Niño, (e) bs.La Niña.frc.neutral, (f) bs.neutral.frc.La Niña, and (g) bs.La Niña.frc.La Niña.

consistency is slightly shifted relative to observations for certain MJO phases and lags. This discrepancy between simulated and observed patterns might result from the linear assumption of the LBM. As discussed in section 2a, certain MJO phases can modulate the basic state that subsequent phases feel, which further changes the required time for Rossby wave propagation (Moore et al. 2010). Thus, the time scale for a MJO teleconnection to develop in extratropical regions might not be constant (e.g., 10 days in this study) and can vary slightly from one phase to the next. This process, however, is absent in the LBM and necessitates investigation in future studies. Regardless this modest bias, Fig. 4 shows that both the El Niño basic states (Fig. 4b) and the El Niño MJO forcing (Fig. 4c) dramatically decrease the pattern consistency of the MJO teleconnections. When both are taken into account, the pattern consistency decrease can exceed $50 \%$ (Fig. 4d). For the La Niña years (the third row of Fig. 4), the effects of the basic state and the MJO forcing compete. The La Niña year basic states increase the pattern consistency while the La Niña MJO forcing decreases the pattern consistency of MJO teleconnections compared to the neutral state. Therefore, the net influence from La Niña on the consistency of MJO teleconnections is modest (i.e., difference between Figs. 4a and 4g). We also examined the result with different domain sizes as well as the location of the eastern and western boundaries of domain. When a bigger domain is used, the pattern consistency decreases due to increased degrees of freedom. In addition, the amplitude of the pattern consistency also decreases when we move the domain eastward, which may result from limitations of the LBM in simulating the teleconnection patterns over northeastern North America and the Atlantic. Regardless of the change in amplitude, the results are qualitatively unchanged with modest modifications to the domain. In the next two subsections, the role of variation in basic states and the MJO forcing over different ENSO climate states in affecting the MJO teleconnection will be examined in more detail.

\section{c. The role of the basic state}

Figures $4 \mathrm{~b}$ and $4 \mathrm{e}$ indicate that La Niña basic states favor a higher pattern consistency for MJO teleconnections relative to El Niño years. As a first step to address the dynamics responsible for this interannual variability of MJO pattern consistency, the linearized 

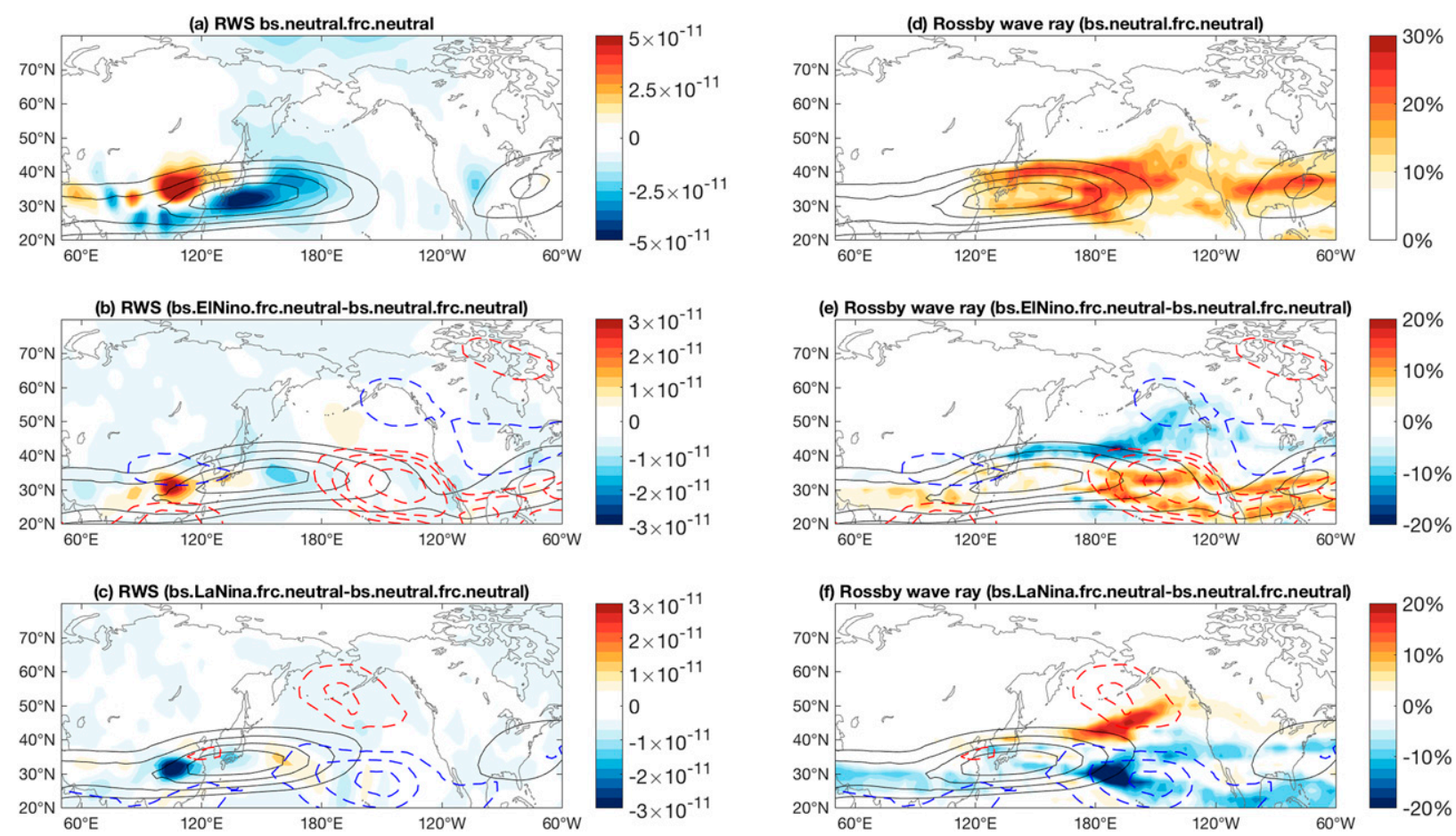

FIG. 5. (a) Ensemble mean MJO phase-6 Rossby wave source in the simulation of bs.neutral.frc.neutral. The difference of the ensemble mean Rossby wave source between simulations of (b) bs.El Niño.frc.neutral and bs.neutral.frc.neutral, and (c) bs.La Niña.frc.neutral and bs.neutral.frc.neutral. Results for lags 0-5 are displayed in (a)-(c). (d) The Rossby wave ray density based on the neutral year basic states. (e) The difference of the ray density between (f) El Niño year basic states and neutral basic states and (g) La Niña year basic states and neutral basic states. The solid contours are the 200-hPa zonal wind at 35, 45, 55, and $65 \mathrm{~m} \mathrm{~s}^{-1}$. The dashed contours are the difference of 200-hPa zonal wind between El Niño or La Niña and neutral year basic states. Red colors are positive values, starting at $4 \mathrm{~m} \mathrm{~s}{ }^{-1}$ with an interval of $4 \mathrm{~m} \mathrm{~s}^{-1}$. Blue colors are negative values, starting at $-4 \mathrm{~m} \mathrm{~s}^{-1}$ with an interval of $4 \mathrm{~m} \mathrm{~s}^{-1}$.

Rossby wave source based on (3) is examined for the three ensemble simulations: bs.neutral.frc.neutral, bs.El Niño.frc.neutral, and bs.La Niña.frc.neutral. The results are shown in Figs. 5a-c. The shading in Fig. 5a is the composite MJO phase-6 Rossby wave source averaged over the 30 ensemble members from the simulation of bs.neutral.frc.neutral (lag 0-5). Phase 6 is one of the MJO phases characterized by the high pattern consistency at lag 10-15, although other phases with high pattern consistency give similar results. The reason for focusing on phase 6 , lag $0-5$ is that the Rossby wave source takes less than 5 days to develop near the subtropical jet after a given forcing in the tropics. This Rossby wave source then takes an additional 10 days or so to influence PNA regions according to Tseng et al. (2019). MJO phase 6 is one of a few phases favoring robust teleconnection signals while the enhanced consistency at short forecast leads for certain phases (e.g., phase 8 , lag $0-5$ ) is actually caused by the delayed signals of teleconnections generated by earlier MJO phases. Thus, focusing on the Rossby wave source pattern at phase 6 , lag $0-5$ is a reasonable choice. The dipole Rossby source pattern across the subtropical jet (to the east and west of the jet entrance regions) has been documented in previous studies to lead to a more consistent MJO teleconnection pattern due to the constructive interference of Rossby waves emanating from the positive and negative source regions (Seo and Lee 2017; Tseng et al. 2019). In general, a more defined dipole structure of the Rossby wave source leads to a higher MJO teleconnection pattern consistency (Fig. 11 in Tseng et al. 2019).

The shading in Figs. 5b and 5c shows the difference between the composited Rossby wave source between the simulations of bs.El Niño.frc.neutral and bs.La Niña.frc.neutral, respectively, and bs.neutral.frc.neutral. The solid contours are the boreal winter mean zonal wind at $200 \mathrm{hPa}$ for different climate states, and the dashed contours represent the change in mean zonal wind during the ENSO periods relative to neutral conditions (i.e., El Niño - neutral or La Niña - neutral). The most notable variations on interannual time scales show up in the western center of the Rossby wave source dipole. Previous studies have demonstrated that the western center of Rossby wave source is mostly determined by the anomalous divergence in a region of 
climatological positive vorticity [i.e., $-\bar{\zeta} \nabla \cdot \mathbf{v}_{X}^{\prime}$ in (3), Sardeshmukh and Hoskins 1988]. During El Niño years, the western Rossby wave source center is enhanced due to increased cyclonic vorticity in the subtropical jet, with opposite behavior during La Niña years. The result of this Rossby wave source analysis contradicts what is shown in Fig. 4 since an enhanced dipole-like Rossby wave source pattern favors a more robust teleconnection signal rather than decreases the pattern consistency. This implies that the concept of Rossby wave source interference cannot be used to explain the interannual variability of the MJO teleconnection pattern consistency shown in Figs. $4 \mathrm{~b}$ and $4 \mathrm{e}$.

Another possible factor for the difference between Figs. $4 \mathrm{~b}$ and $4 \mathrm{e}$ is the interannual variability of the subtropical jet in the northeast Pacific (around $180^{\circ}-$ $120^{\circ} \mathrm{W}$ ) and its effect on Rossby wave propagation. During the El Niño years, the subtropical jet expands eastward and equatorward (the red dashed contour in Fig. 5e), while the subtropical jet in La Niña years is characterized by westward retraction and poleward shift (the red and blue dashed contours in Fig. 5f). As discussed in Hoskins and Ambrizzi (1993), the subtropical jet can act as a waveguide. High stationary wavenumbers at the core of the jet and slow meridional group velocity make stationary Rossby waves refract toward the jet core and act as a trapping mechanism. To explore how the jet variations on interannual time scales influence the pattern consistency of MJO teleconnections, a wave seeding and Rossby wave tracing algorithm is applied over different climate states as described in section 2. Since the MJO teleconnection is quasi-stationary, we only consider $\omega=0$ in this study, which further constrains total stationary wavenumber $K_{s}=\sqrt{\overline{\bar{\zeta}_{y}} / \bar{u}_{\psi}}=\sqrt{\beta^{*} / \bar{u}_{\psi}}$ [Eq. (6)]. Effective beta is defined as $\beta^{*}=\beta-\left(\partial^{2} \bar{U} / \partial y^{2}\right)$, where $\beta$ is the meridional gradient of the planetary vorticity and $\partial^{2} \bar{U} / \partial y^{2}$ is constructed from the basic state zonal wind. Rossby waves with initial zonal wavenumber $k=1,2,3,4$ are used, consistent with the scale of the Rossby wave source and convective scales of the MJO. Since the basic state zonal wind limits the maximum values of the total stationary wavenumber, Rossby waves with initial zonal wavenumber higher than 4 can lead to exponential growth or decay of wave amplitude because $l$ is imaginary. Thus, we only focus on waves able to propagate $(k=1-4)$. For each grid point with an amplitude of Rossby wave source greater than $2 \times 10^{-11}\left(\mathrm{~s}^{-2}\right)$, a Rossby wave ray is initiated and tracked for 15 days. Specifically, each grid point with Rossby wave source amplitude greater than $2 \times 10^{-11}\left(\mathrm{~s}^{-2}\right)$ initiates four rays, which overall yields about 200 rays for one climate state and one simulation. The density of the ray paths is then calculated as the number of ray paths over a grid cell of $2.5^{\circ} \times 2.5^{\circ}$ divided by the total number of ray paths, where each ray is equally weighted. Figure $5 \mathrm{~d}$ shows the density of the ray paths in the simulation of bs.neutral.frc.neutral. The regions with the highest ray path density are spatially collocated with the subtropical jet, consistent with trapping of the waves by the jet. A notable northward extension of ray paths is found at the jet exit. Figures $5 \mathrm{e}$ and $5 \mathrm{f}$ depict the density change in the ray paths over different ENSO states. In El Niño years, the eastward extension of the subtropical jet leads to an eastward shift of the ray paths and decreased ray density in the Gulf of Alaska. In contrast, the northward shift and contraction of the subtropical jet and ray paths in La Niña years increases the ray density in the Gulf of Alaska.

To support the results in Fig. 5, Fig. 6 illustrates the boreal winter averaged effective beta [i.e., $\beta^{*}$ or $\bar{\zeta}_{y}$ in (5)] and the total stationary wavenumber on Mercator projection in the two ENSO states. The term $\beta^{*}$ represents the restoring force of Rossby waves, and wave propagation is only possible in regions with positive $\beta^{*}$. Figures $6 \mathrm{a}$ and $6 \mathrm{~b}$ show that regions with positive and large $\beta^{*}$ are spatially collocated with the jet. Regions of high maximum $\beta^{*}$ are more continuous across the Pacific and North America during El Niño years than La Niña years. The basic state zonal wind and $\beta^{*}$ can be used to define a total stationary wavenumber $\left(K_{s}=\sqrt{\bar{\zeta}_{y} / \bar{u}_{\psi}}\right)$, which is shown in Figs. 6c and 6d. Based on Snell's law in optics, Hoskins and Ambrizzi (1993) demonstrated that stationary Rossby waves are refracted toward regions with large stationary wavenumber, consistent with the waveguide effect described above. In El Niño years, the waveguide (e.g., regions with high $K_{s}$ ) spans from the Pacific to the Atlantic (i.e., $K_{s}=4$ contours), which makes Rossby waves less likely to propagate northward, especially for high zonal wavenumbers. Thus, the ray density in the Gulf of Alaska is decreased in El Niño years (Fig. 5e). However, the northward shift of the waveguide in La Niña years indicates that shorter waves (i.e., $k=3,4$ ) have expanded influence in extratropical regions, consistent with increases in ray density around British Columbia and the Gulf of Alaska (Fig. 5f).

Northward propagating Rossby waves near the exit regions of the subtropical jet plays an important role in generating the PNA pattern. Decreased production of northward propagating waves in El Niño years implies a decreased modulation of extratropical geopotential height by MJO teleconnections. In contrast, an increased density of northward propagating waves in La Niña years enhances the MJO's modulation of extratropical Z500. The pattern consistency of teleconnections represents the amplitude of modulation by the MJO. Thus, these shifts in ray paths over different ENSO states agree with the results on MJO teleconnection pattern consistency change shown in Figs. $4 \mathrm{~b}$ and $4 \mathrm{e}$. This ray tracing analysis provides an 

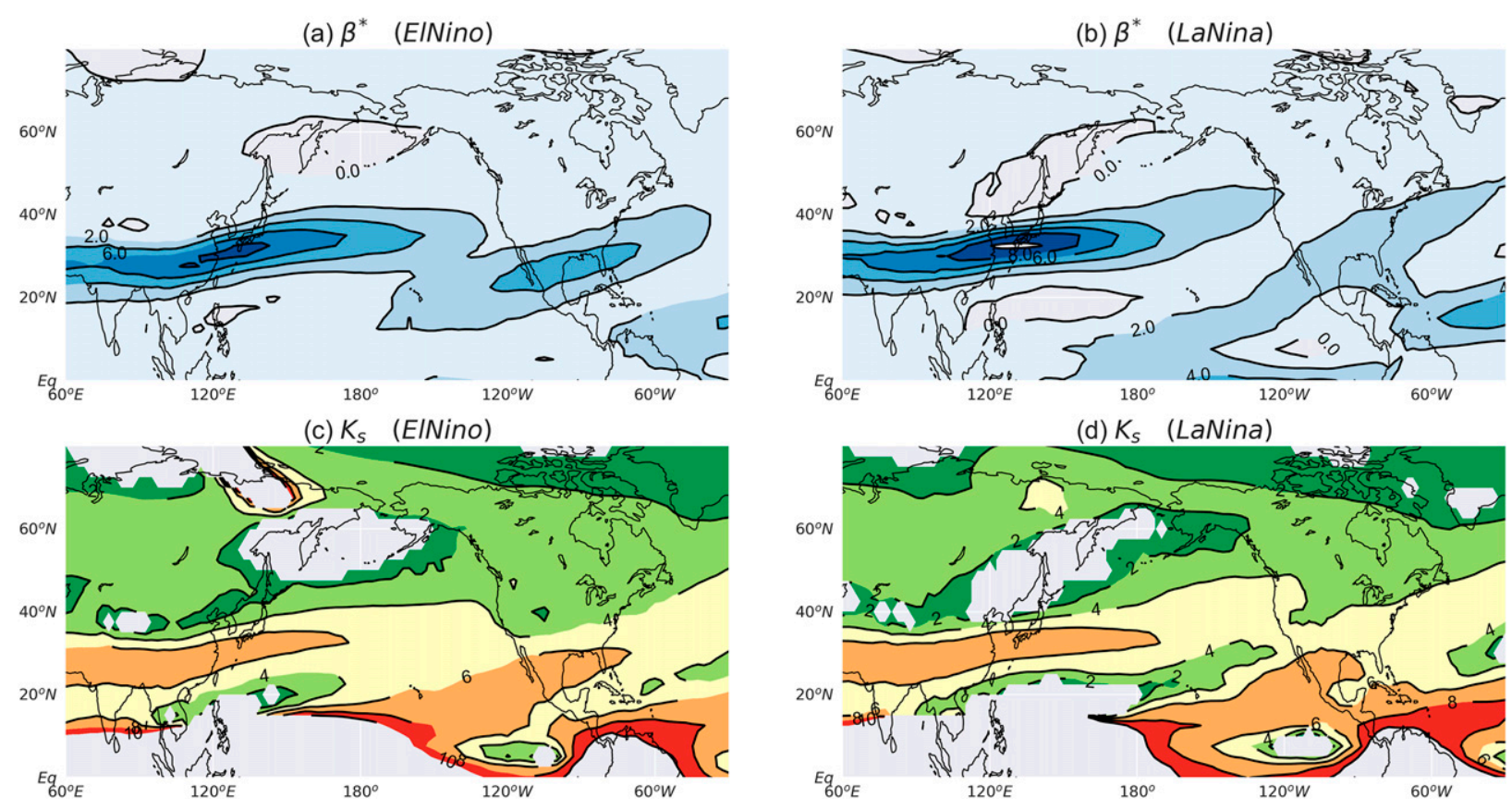

FIG. 6. The boreal winter averaged effective $\beta\left[10^{-11}(\mathrm{~ms})^{-1}\right]$ in (a) El Niño years and (b) La Niña years. Stationary Rossby wavenumber in (c) El Niño years and (d) La Niña years.

indication of how propagation pathways change on interannual time scales due to changes in the basic state. Since there is no sign information associated with these rays, they do not provide information on the constructive or destructive interference of geopotential height anomalies initiated by MJO forcing from different regions.

\section{d. The role of $M J O$ forcing}

Last, we focus on the role of MJO forcing in modulating pattern consistency by analyzing three simulations: bs.neutral.frc.neutral, bs.neutral.frc.El Niño, and bs.neutral.frc.La Niña. All three simulations have identical basic states, but with the MJO forcing varied across the different ENSO states. This investigation highlights how the Rossby wave source pattern is affected by variations in MJO forcing. Figure 7a shows the MJO phase-6 Rossby wave source (shading; north of $20^{\circ} \mathrm{N}$ ), column-integrated Q1 (shading; south of $20^{\circ} \mathrm{N}$ ) and the 200-hPa anomalous divergent flow (vectors) averaged from lag 0 to lag 5. While only MJO phase 6 is shown, other phases producing a robust teleconnection show similar results. As discussed above, Rossby waves forced by opposite-signed Rossby wave sources on either side of the subtropical jet (i.e., dipole structure) can constructively interfere to produce consistent midlatitude geopotential patterns. Figure 7a suggests that the western center of the dipole Rossby wave source is dominated by anomalous convergence in a region of high climatological vorticity $\left(-\bar{\zeta} \nabla \cdot \mathbf{v}_{\chi}^{\prime}\right)$, while the eastern center results from the negative climatological vorticity advection by the anomalous divergent flow $\left(-\mathbf{v}_{\chi} \cdot \nabla \bar{\zeta}\right)$.

Figures $7 \mathrm{~b}$ and $7 \mathrm{c}$ show the $200-\mathrm{hPa}$ divergent wind (i.e., $\mathbf{v}_{\chi}^{\prime}$, vectors) from the simulations bs.neutral.frc.El Niño and bs.neutral.frc.La Niña and the differences in Rossby wave source (shading north of $20^{\circ} \mathrm{N}$ ) between the simulations of bs.neutral.frc.El Niño and bs.neutral.frc.La Niña with and bs.neutral.frc.neutral. The color contours in Figs. $7 \mathrm{~b}$ and $7 \mathrm{c}$ are identical to the shading north of $20^{\circ} \mathrm{N}$ in Fig. 7 a (see figure caption). To the south of $20^{\circ} \mathrm{N}$, Figs. $7 \mathrm{a}-\mathrm{c}$ show the corresponding column-integrated $Q_{1}$ anomalies from ensemble mean provided to the three simulations. For El Niño year MJO forcing (i.e., Fig. 7b), enhanced northward divergent flow occurs over the domain (i.e., vectors in Fig. $7 \mathrm{~b}$, around $30^{\circ} \mathrm{N}-60^{\circ} \mathrm{N}$ and $60^{\circ} \mathrm{E}-150^{\circ} \mathrm{E}$ ), related to enhanced convection across the western and central Pacific at lag 0-5 (i.e., shading around the equator and $\left.180^{\circ}\right)$. Strong northward divergent flow on the north flank of the subtropical jet leads to anomalous divergence in the western center of the dipole Rossby wave source (around $40^{\circ} \mathrm{N}$ and $115^{\circ} \mathrm{E}$ in Fig. $7 \mathrm{~b}$ ) and offsets the convergence typically found there $\left(40^{\circ} \mathrm{N}\right.$ and $115^{\circ} \mathrm{E}$ in Fig. 7a). Thus, the positive western Rossby wave source shown in Fig. 7a is greatly reduced in El Niño years. A less dipole-like Rossby wave source in El Niño years supports the less consistent MJO teleconnection in Fig. 4c than Fig. 4a. During La Niña, the changes in the divergent flow and the Rossby wave source relative 
(a) RWS (bs.neutral.frc.neutral), 200-hPa divergent wind (bs.neutral.frc.neutral) Column-integrated Q1(bs.neutral.frc.neutral)

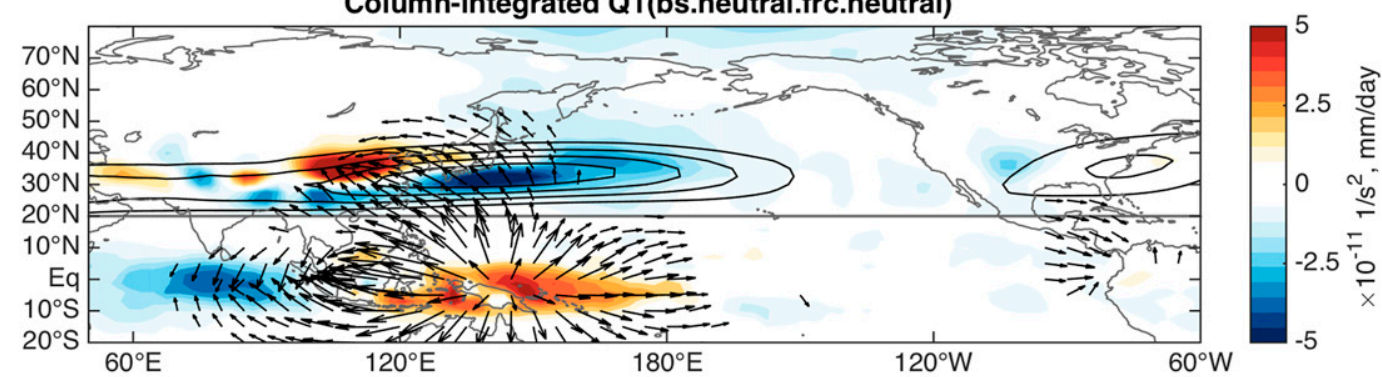

(b) RWS (bs.neutral.frc.EINino-bs.neutral.frc.neutral), 200-hPa divergent wind (bs.neutral.frc.EINino) Column-integrated Q1(bs.neutral.frc.EINino)

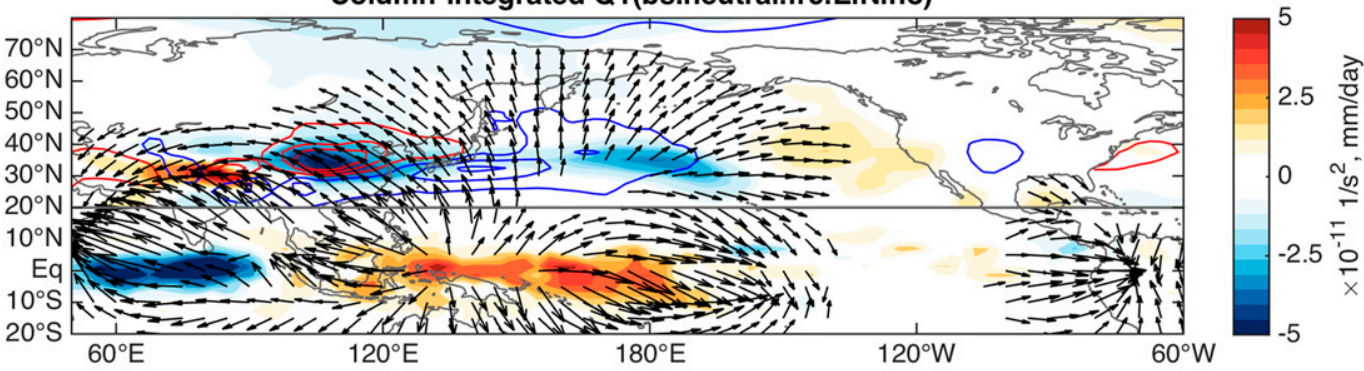

(c) RWS (bs.neutral.frc.LaNina-bs.neutral.frc.neutral), 200-hPa divergent wind (bs.neutral.frc.LaNina) Column-integrated Q1(bs.neutral.frc.LaNina)

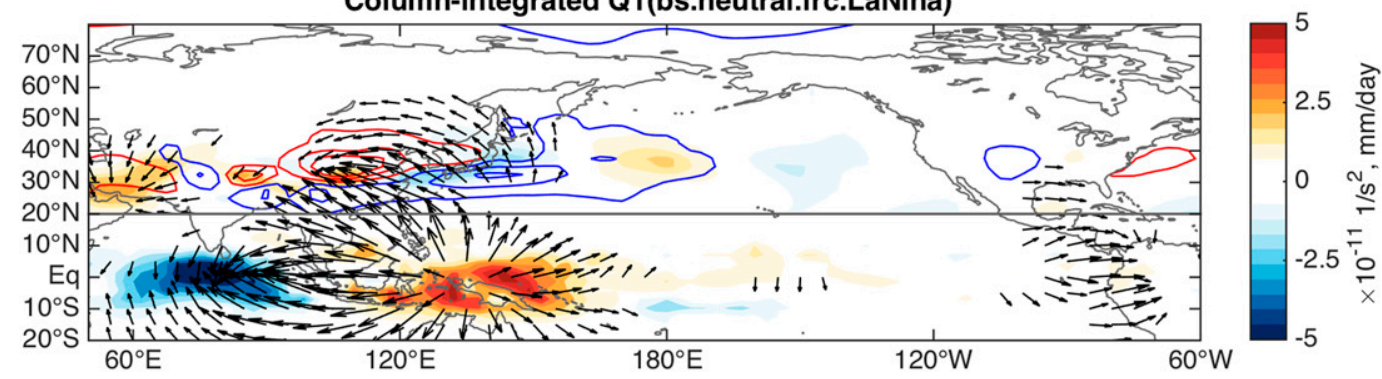

FIG. 7. North of $20^{\circ} \mathrm{N}$ : the MJO phase- 6 Rossby wave source averaged over lag 0-5 (shading; $10^{-11} \mathrm{~s}^{-2}$ ) for (a) bs.neutral.frc.neutral, (b) the difference between bs.neutral.frc.El Niño and bs.neutral.frc.neutral, and (c) the difference between bs.neutral.frc.La Niña and bs.neutral.frc.neutral. The contours in (a) are 200-hPa mean zonal wind from neutral years at 35, 45, 55, and $65 \mathrm{~m} \mathrm{~s}^{-1}$. The color contours in (b) and (c) are identical to the shading in (a). South of $20^{\circ} \mathrm{N}$ : column-integrated $Q 1$ averaged over lag 0-5 (shading; mm day ${ }^{-1}$ ) for three simulations: (a) bs.neutral.frc.neutral, (b) bs.neutral.frc.El Niño, and (c) bs.neutral.frc.La Niña. Over the whole domain the vectors shows the 200-hPa divergent flow $\left(\mathrm{m} \mathrm{s}^{-1}\right)$ averaged over lag 0-lag 5 for bs.neutral.frc.neutral in (a), bs.neutral.frc.El Niño in (b), and bs.neutral.frc.La Niña in (c). Vector length is proportional to the real magnitude of divergent wind anomalies with magnitudes smaller than $0.2 \mathrm{~m} \mathrm{~s}^{-1}$ omitted. Except for the 200-hPa mean zonal wind in (a), all variables shown here are anomalous fields.

to neutral conditions are modest (Fig. 7c). However, the Rossby wave source pattern in La Niña years slightly shifts westward, which reflects the westward shift of MJO convection in La Niña years compared to neutral or El Niño years. Again, the magnitude of these changes in La Niña years is relatively small compared to that in El Niño years.
For later time lags (lag 15-20), both bs.neutral.frc.El Niño and bs.neutral.frc.La Niña show a less dipole-like Rossby wave source pattern across the subtropical jet (figure not shown). A less dipole-like pattern becomes even more apparent for bs.neutral.frc.La Niña at lags 15-20 than at earlier time lags. In La Niña years, the eastward propagation of MJO forcing is less expansive 
(a) RWS (bs.neutral.frc.neutral)

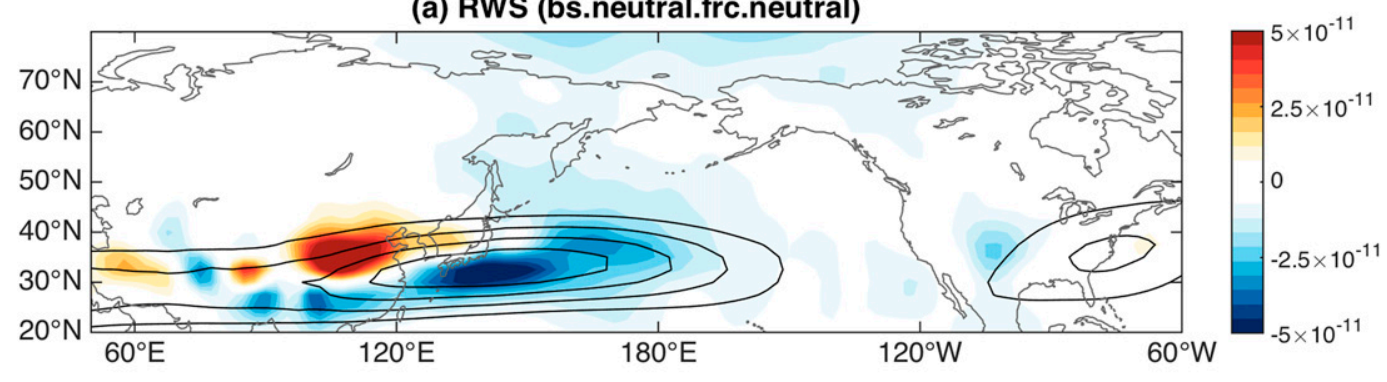

(b) RWS (bs.EINino.frc.EINino)

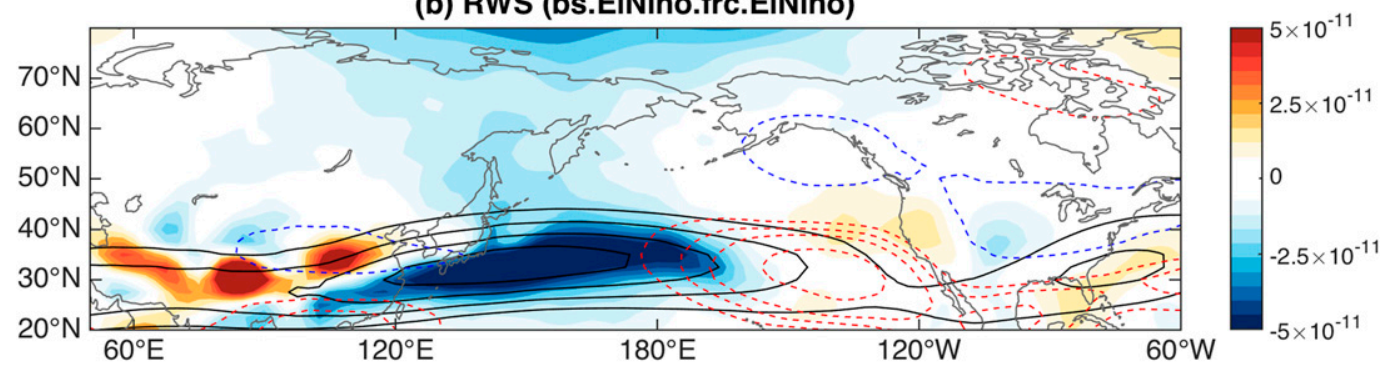

(c) RWS (bs.LaNina.frc.LaNina)

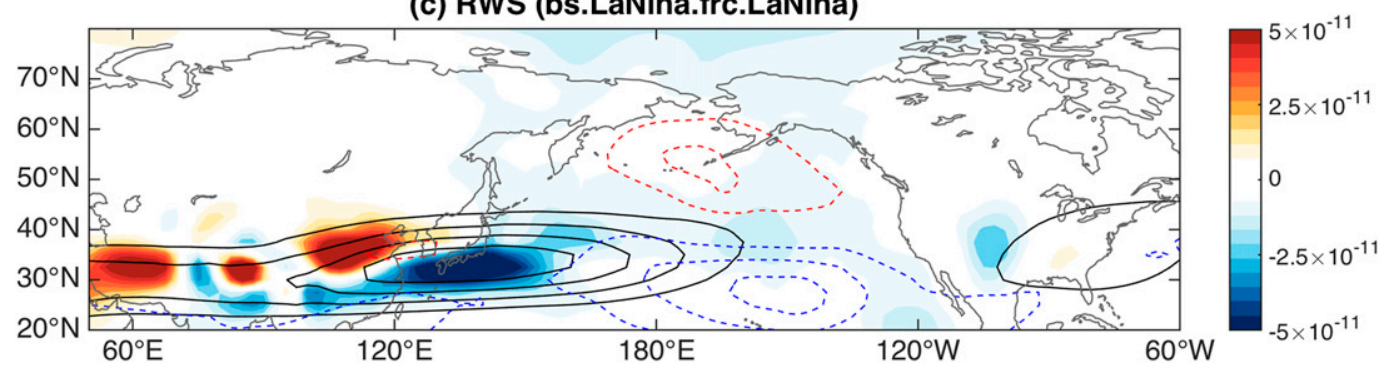

FIG. 8. The MJO phase-6 Rossby wave source (lag 0-5) in the simulations (a) bs.neutral.frc.neutral, (b) bs.El Niño.frc.El Niño, and (c) bs.La Niña.frc.La Niña $\left(\mathrm{s}^{-2}\right)$. Solid contours are the 200 -hPa mean zonal wind at $35,45,55$, and $65 \mathrm{~m} \mathrm{~s}^{-1}$ in three different climate states. The dashed contours in (b) and (c) are the difference in 200-hPa mean zonal wind between the two ENSO states and the neutral years. Blue represents negative values and red positive values. The dashed contours start at 4 and $-4 \mathrm{~m} \mathrm{~s}^{-1}$ with an interval of $4 \mathrm{~m} \mathrm{~s}^{-1}$.

and MJO events do not maintain strength as long compared to neutral and El Niño years [see Figs. $3 \mathrm{a}$ and $3 \mathrm{~b}$ in Wei and Ren (2019)], which may help explain why the dipole Rossby wave source becomes less clear at later lags. Thus, the pattern consistency shown at later lags (>lag 25) of Fig. 4f is smaller than in Fig. 4a. Less continuous propagation of MJO convection likely results from suppressed convective activity in the western and central Pacific caused by La Niña year SST cooling.

\section{Conclusions and remarks}

The role of tropical heating in modulating the extratropical circulations has been extensively investigated since the 1980s, including on interannual and intraseasonal time scales. Since the MJO is one of the dominant modes of heating on the subseasonal time scales, it is an important source of S2S predictability. However, the MJO's ability to modulate extratropical weather varies interannually. This study explored the key mechanisms determining variability in MJO teleconnection pattern consistency over different ENSO states. By conducting ensemble simulations in a linear baroclinic model by alternately fixing or varying MJO forcing or the basic state, the impact of these factors for modulating the consistency of MJO teleconnection patterns was isolated. Results indicate that the pattern consistency of MJO teleconnections from event to event decreases dramatically in El Niño years relative to neutral conditions, while $\mathrm{MJO}$ teleconnections in $\mathrm{La}$ Niña years are characterized by only small changes. In reality, both basic states and MJO forcing can change together and Fig. 8 summarizes the joint influence from both factors. From the basic state perspective (contours 
in Fig. 8), the southeastward extension of the subtropical jet in El Niño years decreases the likelihood of Rossby wave propagation into the Gulf of Alaska, consistent with a reduction in $\mathrm{MJO}$ teleconnection pattern consistency in the North Pacific and North America. By contrast, a northward shift and westward retraction of the jet in La Niña years increases the possibility of wave propagation into the extratropics, which increases the pattern consistency. From an MJO forcing perspective (shading in Fig. 8), the El Niño year MJO forcing weakens the dipole Rossby wave source pattern across the subtropical jet, which reduces the constructive interference of the wave signals in midlatitudes emanating from both centers. This feature is especially apparent for both El Niño and La Niña years at later lags (not shown). A less dipole-like Rossby wave source pattern over both ENSO states thus acts to reduce the pattern consistency of MJO teleconnections.

This study provides a likely explanation for the interannual variability of MJO teleconnection pattern consistency. However, some questions remain unanswered. First, what process determines the interannual variability of MJO convective propagation? Although previous studies have shown that MJO convection propagates slower in La Niña than the El Niño years, the mechanisms responsible for a more successive $\mathrm{MJO}$ life cycle in $\mathrm{El}$ Niño years have not been examined. Second, in this study, the linear Rossby wave theory is used for approximating wave solutions, which assumes the basic state varies slowly in space and time. However, wave-mean flow interactions between MJO teleconnections and the subtropical jet can alter on intraseasonal time scales. How such feedback processes influence the robustness of MJO teleconnections is still unclear. Third, climate model projections indicate that an El Niño-like warming pattern may develop in a future climate forced by increasing greenhouse gas concentrations. How these changes to the basic state due to the anthropogenic warming influences the predictability of extratropical weather is an area of ongoing research.

Acknowledgments. We thank the editor Isaac Held, George Kiladis, and two anonymous reviewers for their constructive criticism that led to substantial improvements in the manuscript. We thank the members in CSU dynamics group for helpful comments on the analysis. We also thank Dr. Stephanie Henderson for providing a tutorial on the LBM and Dr. Watanabe for the use of his model in this research. This research has been conducted as part of the NOAA MAPP S2S Prediction Task Force and supported by NOAA Grant NA16OAR4310064. EDM was also supported by NSF Grant AGS-1841754, and NOAA Grants NA18OAR4310268 and NA18OAR4310299.

\section{REFERENCES}

Adames, Á. F., and D. Kim, 2016: The MJO as a dispersive, convectively coupled moisture wave: Theory and observations. J. Atmos. Sci., 73, 913-941, https://doi.org/10.1175/JAS-D-15-0170.1.

Bjerknes, J., 1969: Atmospheric teleconnections from the equatorial Pacific. Mon. Wea. Rev., 97, 163-172, https://doi.org/ 10.1175/1520-0493(1969)097<0163:ATFTEP $>2.3$.CO;2.

Christiansen, B., 2019: Analysis of ensemble mean forecasts: The blessings of high dimensionality. Mon. Wea. Rev., 147, 16991712, https://doi.org/10.1175/MWR-D-18-0211.1.

Dee, D. P., and Coauthors, 2011: The ERA-Interim reanalysis: Configuration and performance of the data assimilation system. Quart. J. Roy. Meteor. Soc., 137, 553-597, https://doi.org/ 10.1002/qj.828.

Hamill, T. M., and G. N. Kiladis, 2014: Skill of the MJO and Northern Hemisphere blocking in GEFS medium-range reforecasts. Mon. Wea. Rev., 142, 868-885, https://doi.org/ 10.1175/MWR-D-13-00199.1.

Henderson, S. A., and E. D. Maloney, 2018: The impact of the Madden-Julian Oscillation on high-latitude winter blocking during El Niño-Southern Oscillation events. J. Climate, 31, 5293-5318, https://doi.org/10.1175/JCLI-D-17-0721.1.

, - — , and E. A. Barnes, 2016: The influence of the Madden-Julian Oscillation on Northern Hemisphere winter blocking. J. Climate, 29, 4597-4616, https://doi.org/10.1175/JCLI-D-15-0502.1.

Hendon, H. H., M. C. Wheeler, and C. Zhang, 2007: Seasonal dependence of the MJO-ENSO relationship. J. Climate, 20, 531543, https://doi.org/10.1175/JCLI4003.1.

Hirota, N., and M. Takahashi, 2012: A tripolar pattern as an internal mode of the East Asian summer monsoon. Climate Dyn., 39, 2219-2238, https://doi.org/10.1007/s00382-012-1416-y.

Hoskins, B. J., and D. J. Karoly, 1981: The steady linear response of a spherical atmosphere to thermal and orographic forcing. J. Atmos. Sci., 38, 1179-1196, https://doi.org/10.1175/15200469(1981)038<1179:TSLROA > 2.0.CO;2.

- and T. Ambrizzi, 1993: Rossby wave propagation on a realistic longitudinally varying flow. J. Atmos. Sci., 50, 1661-1671, https:// doi.org/10.1175/1520-0469(1993)050<1661:RWPOAR >2.0.CO;2.

Jin, F.-F., 1997: An equatorial ocean recharge paradigm for ENSO. Part I: Conceptual model. J. Atmos. Sci., 54, 811-829, https:// doi.org/10.1175/1520-0469(1997)054<0811:AEORPF>2.0.CO;2.

_ L.-L. Pan, and M. Watanabe, 2006: Dynamics of synoptic eddy and low-frequency flow interaction. Part I: A linear closure. J. Atmos. Sci., 63, 1677-1694, https://doi.org/10.1175/ JAS3715.1.

Kanamori, H., T. Yasunari, and K. Kuraji, 2013: Modulation of the diurnal cycle of rainfall associated with the MJO observed by a dense hourly rain gauge network at Sarawak, Borneo. J. Climate, 26, 4858-4875, https://doi.org/10.1175/JCLI-D-12-00158.1.

Karoly, D. J., 1983: Rossby wave propagation in a barotropic atmosphere. Dyn. Atmos. Oceans, 7, 111-125, https://doi.org/ 10.1016/0377-0265(83)90013-1.

Liebmann, B., H. H. Hendon, and J. D. Glick, 1994: The relationship between tropical cyclones of the western Pacific and Indian Oceans and the Madden-Julian Oscillation. J. Meteor. Soc, 72, 401-412, https://doi.org/10.2151/jmsj1965.72.3_401.

Madden, R. A., and P. R. Julian, 1971: Detection of a 40-50 day oscillation in the zonal wind in the tropical Pacific. J. Atmos. Sci., 28, 702-708, https://doi.org/10.1175/1520-0469(1971) 028<0702:DOADOI $>2.0 . \mathrm{CO} ; 2$.

Maloney, E. D., and D. L. Hartmann, 2000: Modulation of hurricane activity in the Gulf of Mexico by the Madden-Julian 
Oscillation. Science, 287, 2002-2004, https://doi.org/10.1126/ science.287.5460.2002.

Moon, J.-Y., B. Wang, and K.-J. Ha, 2011: ENSO regulation of MJO teleconnection. Climate Dyn., 37, 1133-1149, https:// doi.org/10.1007/s00382-010-0902-3.

Moore, A. M., and R. Kleeman, 1999: Stochastic forcing of ENSO by the intraseasonal oscillation. J. Climate, 12, 1199-1220, https:// doi.org/10.1175/1520-0442(1999)012<1199:SFOEBT>2.0.CO;2.

Moore, R. W., O. Martius, and T. Spengler, 2010: The modulation of the subtropical and extratropical atmosphere in the Pacific basin in response to the Madden-Julian oscillation. Mon. Wea. Rev., 138, 2761-2779, https://doi.org/10.1175/2010MWR3194.1.

Mundhenk, B. D., E. A. Barnes, and E. D. Maloney, 2016: Allseason climatology and variability of atmospheric river frequencies over the North Pacific. J. Climate, 29, 4885-4903, https://doi.org/10.1175/JCLI-D-15-0655.1.

,,--- , and C. F. Baggett, 2018: Skillful subseasonal prediction of atmospheric river activity based on the MaddenJulian Oscillation and the quasi-biennial oscillation. $n p j$ Climate Atmos. Sci., 1, 20177, https://doi.org/10.1038/S41612017-0008-2.

Newman, M., and P. D. Sardeshmukh, 1998: The impact of the annual cycle on the North Pacific/North American response to remote low-frequency forcing. J. Atmos. Sci., 55, 1336-1353, https://doi.org/10.1175/1520-0469(1998)055<1336:TIOTAC> 2.0.CO;2.

Pang, B., Z. S. Chen, Z. P. Wen, and R. Y. Lu, 2016: Impacts of two types of El Niño on the MJO during boreal winter. $A d v$. Atmos. Sci., 33, 979-986, https://doi.org/10.1007/s00376-016$5272-2$.

Pohl, B., and A. J. Matthews, 2007: Observed changes in the lifetime and amplitude of the Madden-Julian oscillation associated with interannual ENSO sea surface temperature anomalies. J. Climate, 20, 2659-2674, https://doi.org/10.1175/JCLI4230.1.

Sardeshmukh, P.-D., and B.-J. Hoskins, 1988: The generation of global rotational flow by steady idealized tropical divergence. J. Atmos. Sci., 45, 1228-1251, https://doi.org/10.1175/15200469(1988)045<1228:TGOGRF $>2.0$. CO;2.
Seo, K.-H., and H.-J. Lee, 2017: Mechanisms for a PNA-like teleconnection pattern in response to the MJO. J. Atmos. Sci., 74, 1767-1781, https://doi.org/10.1175/JAS-D-16-0343.1.

Straub, K. H., 2013: MJO initiation in the real-time multivariate MJO index. J. Climate, 26, 1130-1151, https://doi.org/10.1175/ JCLI-D-12-00074.1.

Tseng, K.-C., E. A. Barnes, and E. D. Maloney, 2018: Prediction of the midlatitude response to strong Madden-Julian Oscillation events on S2S timescales. Geophys. Res. Lett., 45, 463-470, https://doi.org/10.1002/2017GL075734.

_ - E. Maloney, and E. Barnes, 2019: The consistency of MJO teleconnection patterns: An explanation using linear Rossby wave theory. J. Climate, 32, 531-548, https://doi.org/10.1175/ JCLI-D-18-0211.1.

Vitart, F., 2017: Madden-Julian Oscillation prediction and teleconnections in the S2S database. Quart. J. Roy. Meteor. Soc., 143, 2210-2220, https://doi.org/10.1002/qj.3079.

_ , and Coauthors, 2017: The Subseasonal to Seasonal (S2S) prediction project database. Bull. Amer. Meteor. Soc., 98, 163173, https://doi.org/10.1175/BAMS-D-16-0017.1.

Watanabe, M., and M. Kimoto, 2000: Atmosphere-ocean thermal coupling in the North Atlantic: A positive feedback. Quart. J. Roy. Meteor. Soc., 126, 3343-3369, https://doi.org/10.1002/qj.49712657017.

Wei, Y., and H. Ren, 2019: Modulation of ENSO on fast and slow MJO modes during boreal winter. J. Climate, 32, 7483-7506, https://doi.org/10.1175/JCLI-D-19-0013.1.

Yanai, M., S. Esbensen, and J.-H. Chu, 1973: Determination of bulk properties of tropical cloud clusters from large-scale heat and moisture budgets. J. Atmos. Sci., 30, 611-627, https://doi.org/ 10.1175/1520-0469(1973)030<0611:DOBPOT>2.0.CO;2.

Yoo, C., and S.-W. Son, 2016: Modulation of the boreal wintertime Madden-Julian Oscillation by the stratospheric quasi-biennial oscillation. Geophys. Res. Lett., 43, 1392-1398, https://doi.org/ 10.1002/2016GL067762.

_ S. Lee, and S. B. Feldstein, 2012: Mechanisms of Arctic surface air temperature change in response to the MaddenJulian oscillation. J. Climate, 25, 5777-5790, https://doi.org/ 10.1175/JCLI-D-11-00566.1. 